\title{
Trasformando el país a través de la higiene. Las cartillas técnicas y la revista Rin Rin en las bibliotecas aldeanas de Colombia 1936-1938
}

\author{
Hygiene; the transformation of a country. School \\ handbooks and the "Rin Rin" magazine at villager \\ libraries in Colombia 1936-1938
}

DOI: https://doi.org/10.25100/hye.v16i54.9665

Artículo recibido: 11-06-2019 Artículo aceptado: 12-09-2019

\section{Willian Alfredo Chapman Quevedo}

Historiador egresado de la Universidad del Atlántico,cuenta con un Magíster en Sociedades Históricas y Formas Políticas en Europa de la Universidad Rovira y Virgili de Tarragona (España), y es Doctor en Historia Social y Política Contemporánea por la Universidad Internacional de Andalucía (España).Profesor de planta tiempo completo de la Universidad del Tolima.

Universidad del Tolima, Colombia.

Correo electrónico: wachapmanq@ut.edu.co

ORCID: 0000-0003-2415-1535

Forma de citar este artículo: Chapman Quevedo, Willian Alfredo, Castro Fontalvo, Jesús Ángel y Ángela Lucía Agudelo González. "Trasformando el país a través de la higiene. Las cartillas técnicas y la revista Rin Rin en las bibliotecas aldeanas de Colombia 1936-1938". Historia y Espacio, vol. 16 n 54 (2020): 183-208. Doi.org/10.25100/hye.v16i54.9665

Artículo Tipo 2: de reflexión 


\section{Jesús Ángel Castro Fontalvo}

Historiador graduado de la Universidad del Atlántico y Magíster en Historia de la misma institución. Docente catedrático de la Universidad del Atlántico e integrante del Grupo de Investigaciones Históricas en Educación e Identidad Nacional (Categoría A, Colciencias). Entre sus temas de interés están la historia de la higiene y la salubridad pública, la historia social de la educación y la historia del libro en el Caribe colombiano. Universidad del Atlántico, Colombia.

Correo electrónico: jangelcastro@mail.uniatlantico.edu.co

ORCID: 0000-0001-6966-3230

\section{Ángela Lucía Agudelo González}

Historiadora grauda de laUniversidad del Atlántico y Magíster en Geografía de la Universidad de los Andes. Profesora de la Universidad del Tolima.

Universidad del Tolima, Colombia.

Correo electrónico:alagudelog@ut.edu.co

ORCID: 0000-0001-7747-3517 


\section{Resumen}

En el presente artículo se analiza el papel que jugaron las cartillas técnicas y la revista Rin Rin en el proceso de modernización de Colombia, bajo el gobierno del liberal Alfonso López Pumarejo. Para el liberalismo, la educación estuvo en la orbita de su proyecto nacional, por lo que las escuelas fueron observadas como los espacios propicios para formar al colombiano modelo. Por lo cual, abordamos el proyecto liberal de las bibliotecas aldeanas y la socialización que estas realizaron del material bibliográfico, lo que les permitió configurar un discurso sobre la higiene y el progreso. Llegamos a la conclusión que existió una preocupación por parte del Estado, en manos de los liberales, por trasformar, a través de la educación, las prácticas y costumbres de la población colombiana y consolidar así el proceso de modernización del país.

Palabras clave: Bibliotecas, cartilla, higiene, liberalismo, progreso

\section{Abstract}

This article analyzes the importance of school handbooks and the "Rin Rin" Magazine within Colombia's modernization under the liberal administration of Alfonso Lopez Pumarejo. It is essential to mention that education was the main goal of the national project; thus, schools represented the accurate place to form the ideal Colombian citizen. Hence, we addressed the liberal project of villager libraries and the socialization they made about the bibliographic resources that permitted the creation of a speech about hygiene and progress. We came to the conclusion that the State along with its liberal administration was interested in transforming the country through education, practices and Colombian customs and so, strengthen the modernization progress of the country.

Key words: Libraries, School Handbooks, Hygiene, Liberalism, Progress 
Willian Alfredo Chapman Quevedo, Jesús Ángel Castro Fontalvo, Ángela Lucía Agudelo González

\section{Trasformando el país a través de la higiene. Las cartillas técnicas y la revista Rin Rin en las bibliotecas aldeanas de Colombia} 1936-1938

\section{Introducción}

Durante el período conocido como la "República Liberal", 1930-1946, se generaron reformas que buscaron impulsar un proceso de modernización política y social del Estado-nación colombiano. Uno de los principales promotores de este proceso fue Alfonso López Pumarejo, quien en su primer gobierno (1934-1938) impulsó una política de Estado conocida como Revolución en marcha.

Este plan de gobierno se ejecutó a través de reformas y proyectos que abarcaron el aparato constitucional, educativo, fiscal y agrario, con el propósito de trasformar las relaciones económicas y sociales existentes hasta ese momento en Colombia, y alcanzar el progreso social y la reorganización del Estado ${ }^{1}$.

Una de sus principales políticas tuvo como eje la educación, que produjo la pérdida de potestad de la Iglesia sobre la dirección de educación pública y se pasó a la libertad de enseñanza tutelada por el Estado². Conla promulgación de la Ley 32 de 1936 se democratizó el ingreso, mediante la igualdad de condiciones, a las instituciones educativas, y se estableció que Ningún establecimiento de

1 Oliver Mora Toscano, "Los dos gobiernos de Alfonso López Pumarejo: Estado, reformas económicas y sociales en Colombia (1934-1938) - (1942-1945)”, Revista Apuntes del Cenes vol. 36, N. . 64 (2017):153-154.

2 César Giraldo, Primera administración López Pumarejo: “La Revolución en Marcha”, Desarrollo económico y social en Colombia. Siglo XX (Bogotá: Universidad Nacional de Colombia, 2001),103. Un intento por establecer una educación laica bajo la tutela del Estado se había realizado durante el período del liberalismo radical en Colombia en el siglo XIX. Véase, Gilberto Loaiza Cano, Sociabilidad, religión y política en la definición de la nación. Colombia, 1820-1886 (Bogotá: Universidad Externado de Colombia, 2011): 329-377. 
educación primaria, secundaria o profesional, podrá negarse a admitir alumnos por motivos de nacimiento ilegítimo, diferencias sociales, raciales o religiosas ${ }^{3}$.

También se crearon las Escuelas Normales Rurales, lo cual se tradujo en cambios importantes en materia educativa, ya que a través ellas se consolidó la profesionalización del cuerpo docente en el país. A lo que se le sumó el impulso a la participación femenina en el magisterio, que consolidó su rol en la docencia ${ }^{4}$. Ambos procesos, aunque se habían iniciado en el siglo XIX con el proyecto republicano, se vieron truncados por factores como las políticas educativas de la llamada Regeneración ${ }^{5}$.

Para el liberalismo, la educación se convirtió en una preocupación de orden nacional ya que consideraba las escuelas como espacios propicios para formar al colombiano modelo. Esta trasformación del ciudadano permitiría que la sociedad se configurara como moderna y progresista. Para lograr este objetivo se necesitaba que el Estado pusiera especial atención a los sectores populares, a sus costumbres, a su modo de vida, a sus prácticas de consumo, considerados, para la época, como parte del atraso y la barbarie que atravesaba el país 6 .

Una de las estrategias utilizadas por parte del ministro de Educación, Luis López de Meza, fue la campaña de Cultura Aldeana y Rural de Colombia, un ambicioso proyecto que buscó integrar los lugares más alejados a la nación y, a su población, a los patrones de modernización buscando que los ciudadanos adquirieran un nuevo modelo de comportamiento ${ }^{7}$. Utilizó medios como la

3 Ley 32 de febrero 20 de 1936. "Sobre igualdad de condiciones para el ingreso a los establecimientos de educación”, Art. 1. . Diario Oficial N. 23.127 (5 de marzo de 1936). Un ejemplo de la puesta en marcha de la citada ley se evidencia en la carta que el comerciante laboyano Luis Felipe Torres dirigió al Ministerio de Educación Nacional en 1937, en la que se quejaba de la discriminación de que era objeto su hija natural por parte de las hermanas del Colegio La Presentación. Willian Alfredo Chapman Quevedo, Sandra Milena Ariño Solano y Jorge Eliécer Cruz Ortiz, Pitalito 200 años de historia (Ibagué: Caza de Libros, 2018). 267.

4 Javier Sáenz, "Reformas normalistas de la primera mitad de siglo (1903-1946)", Revista Educación y Pedagogía. N. ${ }^{\circ} 14$ y 15 (1995): 154-159.

5 Loaiza Cano, Sociabilidad, religión y política, 319-377.

6 Martha Cecilia Herrera, y Carlos Jilmar Díaz, "Bibliotecas y lectores en el siglo XX colombiano: la Biblioteca Aldeana de Colombia”, Revista Educación y Pedagogía vol. XIII, N. ㅇ 29-30 (2001): 103-111.

7 Carlos Jilmar Díaz, "La Campaña de la Cultura Aldeana (1934-1936) en la historiografía de la educación colombiana", Revista colombiana de Educación, N. . 38-39 (1999) https://doi. org/10.17227/01203916.5435 
radio, el cine y las bibliotecas aldeanas, con las cuales se trató de dotar de una colección de libros a todos los pueblos del país.

Con este proyecto de bibliotecas se buscó difundir un nuevo ideal de vida y civilización ${ }^{8}$. Así que, más allá de las intenciones de alfabetizar a la población, se trataba, a través de estos elementos pedagógicos, de una campaña de higienización en las aldeas basada en las consignas de la higiene y la pulcritud. El presente artículo describe y analiza el papel que jugaron las cartillas técnicas y la revista Rin Rin en el proceso de modernización de Colombia.

Para ello, el escrito comprende dos partes. En la primera se aborda el proyecto de las bibliotecas aldeanas, cómo fue su proceso de constitución y cuáles eran los libros que componían su colección, así mismo se considera la revista Rin Rin y sus características de publicación, con el fin de determinar el tipo de material editorial que se ajusta a este análisis. En la segunda parte, se estudia cómo las cartillas y la revista Rin Rin contribuyeron a configurar un discurso sobre la higiene y el progreso que permitió canalizar el anhelo de modernización del primer gobierno de Alfonso López.

\section{Las bibliotecas aldeanas de Colombia}

Uno de los mecanismos que se utilizó para consolidar el progreso en Colombia mediante la Campaña de Cultura Aldeana y Rural fue la creación, en el año de $1934^{9}$, de las bibliotecas aldeanas de Colombia, que se instalaron en municipios y corregimientos del territorio nacional, no solo con el propósito de acercar a la población y ampliar el radio de acción de las prácticas de lectura, sino, como lo ha sugerido el historiador Renán Silva, de crear en las pequeñas poblaciones instituciones culturales que sirvieran de apoyo a las tareas de difusión cultural, impulsadas también a través de otros medios como el cine y la radio ${ }^{10}$. Fue así como:

8 Norbert Elías, El proceso de la civilización: investigaciones sociogenéticas y psicogenéticas (México: Fondo de Cultura Económica, 1987).

9 Las bibliotecas aldeanas se crean con la Ley 12 de 1934 (17 de diciembre). No hay un documento que diga cuándo inició el proceso de implementación porque varió de región en región y estuvo sujeto a las iniciativas de las corporaciones municipales que eran, en últimas, las que debían expedir los acuerdos y hacerse cargo de ellas. Sin embargo, lo que se ha logrado identificar por medio de los despachos de las obras desde la Biblioteca Nacional es que en el mes de agosto de 1935 ya muchas bibliotecas habían empezado a recibir los libros.

${ }^{10}$ Renán Silva, "Libros y lecturas durante la República Liberal: Colombia, 1930-1946” Revista Sociedad y Economía, N. 3 (2002): 141-169. 
Mediante la "Biblioteca Aldeana de Colombia" se buscó difundir nuevos cánones de comportamientos, de sociabilidad, de comercio, [...] en resumidas cuentas, de conocimientos para que, mediante la lectura, fuese difundido el ideal de la sociedad que era deseado. Con esta estrategia se quiso subsanar uno de los inconvenientes que afrontaban las elites, en un periodo de transición política y económica por el que atravesaba Colombia, como lo es el de conformar y consolidar una nueva mentalidad colectiva con los ideales y planteamiento de la modernidad: centralidad política y control social, democracias y desarrollo económico"11.

Estas bibliotecas se instalaron en las poblaciones que tenían entre quinientos y cinco mil habitantes y que contaban con un centro administrativo ${ }^{12}$. Estaban articuladas a un proyecto estatal ambicioso (Cultura Aldeana) que, a través del Ministerio de Educación Nacional, proveía planos arquitectónicos para la construcción de escuelas, profesores ambulantes, inspectores de educación y aparatos de difusión cultural como la radio y el cinematógrafo.

Este proceso de constitución de bibliotecas como forma de consolidar el "progreso nacional" no era exclusivo de Colombia; en Argentina se fueron estableciendo, por todo su territorio, bibliotecas populares buscando satisfacer la necesidad que experimentaban grupos mayoritarios de la población, que tenían entre sus horizontes de expectativas los ideales de una sociedad moderna y de un ciudadano ilustrado ${ }^{13}$. También es cierto que el propósito de establecer las bibliotecas como centros de saber y conocimiento inició su periplo desde el siglo XV, como lo ha mostrado Burke ${ }^{14}$.

Para oficializar la instalación de las bibliotecas en los corregimientos y municipios, el Ministerio de Educación Nacional estableció unos requisitos básicos. Primero, en los corregimientos se debía nombrar un maestro de escuela como director de la biblioteca y remitir a la Biblioteca Nacional el certificado de su posesión; segundo, construir o adecuar un espacio idóneo

${ }^{11}$ Carlos J. Díaz, El pueblo: de sujeto dado a sujeto político por construir. El caso de la "Campaña de Cultura Aldeana” en Colombia (1934-1936) (Bogotá: Universidad Pedagógica Nacional, 2005).

${ }^{12}$ Biblioteca Nacional de Colombia (BNC), "Estatuto de la Aldea Colombiana”, Revista Senderos, vol. $2, \mathrm{~N}^{\circ} 7$ (1934): 3 .

${ }^{13}$ María de los Ángeles Lanzillotta y Micaela Oviedo, “Difundir cultura e ilustración”. Las bibliotecas populares en la trama de la sociabilidad de las poblaciones pampeanas, 19051955”, Historia y Espacio, vol. 14, n. 51 (2018). doi: 10.25100/hye.v14i51.6985.

${ }^{14}$ Peter Burke, Historia social del conocimiento. De Gutenberga a Diderot (Barcelona: Paidós, 2002): 111-152. 
que contara con las condiciones básicas para su instalación ${ }^{15} \mathrm{y}$, por último, enviar una fotografía del inmueble. Los municipios también debían cumplir dichos requisitos y, además, debían expedir un acuerdo por medio del cual el municipio se constituía en patrono de la Biblioteca Aldeana y destinaba una partida anual para la compra de libros ${ }^{16}$.

En Colombia esta iniciativa tuvo gran acogida en algunas poblaciones; en otras, hubo desinterés de las autoridades locales para adquirirlas y, en algunos municipios, aunque sí fueron adquiridas, no prestaban un buen servicio, al punto de que algunas autoridades, como párrocos y directores de escuela, se quejaban de la precariedad del servicio ante los concejos municipales y, por correspondencia, ante la misma Biblioteca Nacional. Así fue, verbigracia, en el municipio de Iquira (Huila), donde una carta dirigida al presidente del concejo municipal le hacía un llamado para que se interesara por el proyecto bibliotecario y por darle cumplimiento al mismo, dado que Luego de haber dictado el acuerdo mediante el cual se constituyó en patrono de la biblioteca aldeana de esa población y apropió algunas sumas de dinero para atender a la construcción de muebles y compra de nuevas obras, no ha dado cumplimiento a esta última parte y ha retirado su apoyo a la biblioteca en mención ${ }^{17}$.

Los bibliotecarios tenían la obligación de enviar a la Biblioteca Nacional las relaciones de las estadísticas de lectores y de los libros que recibían como donaciones de independientes y de la misma Biblioteca. Y, aunque algunos directores enviaron las estadísticas y fueron felicitados por su buena labor, muchas de las peticiones desde la dirección de la Biblioteca Nacional se centraron en solicitarles a los bibliotecarios de las regiones el cumplimiento del envío de los datos de lectores y textos que adquirían para sus colecciones. Un caso muy particular se presentó en López (Cauca), donde el bibliotecario encargado no había notificado a la Biblioteca Nacional el recibo de ninguna colección de libros desde la puesta en marcha de la biblioteca, por lo que el jefe del despacho nacional le solicitó al director de la Escuela Normal para Varones de esa localidad que como hasta la fechano he obtenidonoticias sobre la marchade la

${ }^{15}$ Instrucciones Fundación Bibliotecas Aldeanas. BNC, caja 20, carpeta 171. A pesar de que en el acto legislativo se planteaba que los municipios debían construir o adecuar algunas locaciones para el buen funcionamiento de estas instituciones culturales, en la documentación revisada se logró constatar que muchas de estas bibliotecas funcionaron en escuelas, universidades, estaciones de ferrocarriles y hasta en cárceles, asilos y leprosarios. Para confrontar: Acuerdos Municipales (1935-1937). BNC, Fondo Bibliotecas Aldeanas.

${ }^{16}$ BNC, Fondo Bibliotecas Aldeanas, 2.

${ }^{17}$ BNC, "Copiador de Correspondencia” (Bogotá, 1937): 42. 
Biblioteca Aldeana del Municipio de López, ruégole encarecidamente me haga el favor de averiguar lo que haya sobre este asunto y comunicármelo a la vuelta de correo ${ }^{18}$.

Además de ofrecer el servicio de lectura en esos espacios, las bibliotecas prestaban los libros para que los lectores pudieran leerlos en sus domicilios. Para tener el derecho, el usuario debía dejar la suma de 1,50 pesos m. c. e. ${ }^{19}$ como garantía de devolución de la obra que había solicitado. En caso de deterioro o pérdida del material, esta suma se utilizaba para su reposición ${ }^{20}$. El proceso tuvo como objetivo fortalecer las dinámicas de lectura en las poblaciones vulnerables, y se venía consolidando desde el siglo XIX, cuando un sector de la población colombiana estableció espacios autodidactas de formación y lectura $^{21}$.

Una de las dificultades para la consolidación de las bibliotecas fue la falta de personal cualificado, ya que fungieron, como bibliotecarios, personeros municipales, párrocos y personas reconocidas por su honorabilidad en las localidades. Para subsanar esta dificultad, la Biblioteca Nacional, en su objetivo de organizar las bibliotecas aldeanas, envió con frecuencia libros que ilustraban a estos funcionarios sobre cómo organizar y administrar eficientemente una biblioteca $^{22}$.

El bibliotecario era el responsable de la organización de la biblioteca; debía realizar los inventarios respectivos, procurar incrementar las colecciones a través de donaciones y gestión de recursos ante las autoridades locales, presentar a la Biblioteca Nacional el reporte de lectores cada mes y un informe general sobre las condiciones de funcionamiento de la biblioteca a su cargo ${ }^{23}$.

${ }^{18}$ Ibíd., 118.

${ }^{19}$ Moneda corriente de la época

${ }^{20}$ Instrucciones Fundación Bibliotecas Aldeanas. BNC, caja 20, carpeta 171.

${ }^{21}$ Sobre el fenómeno señalado para el caso colombiano véase el trabajo de Luis Ervin Prado Arellano, "El letrado parroquial", en El siglo diecinueve colombiano, ed. Isidro Vanegas (Bogotá D. C.: Ediciones Plural, 2017) y, para el caso europeo, el texto de Robert Darnton, El diablo en el agua bendita o el arte de la calumnia de Luis XIV a Napoleón (México D. F.: Fondo de Cultura Económica, 2014).

${ }^{22}$ Entre los libros enviados a las bibliotecas aldeanas se destacan dos obras del bibliotecario argentino Alfredo Console: Fundación y organización de Bibliotecas y Hagamos del bibliotecario un profesional. Confrontar en: "Comunicaciones oficiales Atlántico 2" BNC, Comunicaciones Biblioteca Nacional, Fondo Bibliotecas Aldeanas. Caja 3, carpeta 24.

23 "Instrucciones Fundación Bibliotecas Aldeanas". BNC, Comunicaciones Biblioteca Nacional, Fondo Bibliotecas Aldeanas. Caja 20, carpeta 171. 
Otra de las dificultades fue la pérdida de algunos libros en su traslado desde la Biblioteca Nacional hasta las bibliotecas aldeanas del país. El encargado de la distribución fue el Ministerio de Correos, pero la logística de la distribución se vio afectada sobre todo en las regiones más apartadas del país, donde hubo, incluso, dificultades de acceso para realizar las entregas. Por ejemplo, el $24 \mathrm{de}$ marzo de 1937, el director de la Biblioteca Nacional, en carta al director de la Universidad Católica Bolivariana de Medellín (Antioquia), le pedía investigar en la oficina de correspondencia de esa ciudad la pérdida de los libros que le habían sido enviados desde hacía más de un mes y que la Universidad no había recibido. La comunicación rezaba lo siguiente:

Al respecto, manifiesto a usted que el 6 de febrero del año en curso le remití dos cajas que contenían los libros que componen las bibliotecas aldeanas y que tengo en mi poder los comprobantes de recibo en el Ministerio de Correos. Ruégole investigar sobre este particular en la oficina de correos de esa ciudad y comunicarme el resultado de tal investigación, para que en caso de pérdida de los libros en referencia yo pueda dirigirme al Ministro de Correos a fin de que aclare este asunto ${ }^{24}$.

A pesar de estas dificultades, las bibliotecas se pusieron en marcha. Luis López de Meza describía, en las memorias presentadas al Congreso de la República en 1935, así el

[...] modelo de biblioteca con unas cien obras célebres de la intelectualidad colombiana, con otras de autores extranjeros, con cartillas de información técnica elemental y un buen diccionario enciclopédico; para lo cual donde sea posible, aprovechará los servicios de la Biblioteca Nacional, mejor provista al efecto para estas funciones. ${ }^{25}$

Estos textos que conformaban la colección respondían a una necesidad del Estado por crear nuevos tipos de subjetividades en los habitantes del país con el propósito de alcanzar una transformación sociocultural en los pueblos. Los encargados de definir las colecciones de libros que conformaron la Biblioteca Aldeana fueron el ministro de Educación, Luis López de Mesa, y el director de la Biblioteca Nacional, Daniel Samper Ortega.

\footnotetext{
${ }^{24}$ Copiador, 181.

${ }^{25}$ Ministerio de Educación Nacional (MEN), Memoria del ministro de Educación Nacional (Bogotá: MEN, 1935), 62.
} 
Así lograron configurar cuatro grandes colecciones; la primera, de cartillas técnicas, fue asumida en su totalidad por el Ministerio de Educación Nacional. La segunda, de libros denominados por Samper Ortega como de conocimientos generales $^{26}$, estaba compuesta por textos sobre disciplinas que en ese momento comenzaban a ser estudiadas en la enseñanza secundaria ${ }^{27}$, eran textos de instrucción pensados con el objetivo de mejorar las prácticas de trabajo, generar nuevas prácticas de consumo y brindar conocimiento sobre las nuevas técnicas para las industrias.

La tercera fue la denominada Colección Araluce ${ }^{28}$ que comprendía obras de la literatura universal adquiridas a la Casa Araluce, y fue concebida como un conjunto de obras de entretención para sus destinatarios.

Y la cuarta, dedicada a la literatura colombiana, conocida como la Selección Samper Ortega de Literatura Colombiana, constaba de cien volúmenes que recogían las principales obras de autores nacionales, en distintos géneros. En ella se encontraba desde poesías, cuentos y novelas, hasta algunos relacionados con historia, ciencia, periodismo y educación, entre otros ${ }^{29}$.

Estas fueron las colecciones de libros que hicieron parte de las bibliotecas aldeanas. Sin embargo, cada biblioteca recibía donaciones privadas de libros y contaba con fondos para la compra de obras. Por lo que muchas de estas bibliotecas locales tuvieron la posibilidad de ampliar su colección.

De estas colecciones resalta la revista Rin Rin que circuló en áreas urbanas y rurales ${ }^{30} \mathrm{y}$ formaba parte de los libros que iban adquiriendo las bibliotecas,

${ }^{26}$ Esta colección incluía textos de introducción a la Física y a la Química, Economía Política, Geología, Fisiología, Historia de Grecia, Gramática, Geometría, Aritmética, Historia del Arte, entre otras. Para constatar, ver: BNC, "Circular”, Senderos vol. 4, N. ${ }^{\text {s }} 18$ y 19 (1935): 87.

${ }^{27}$ Renán Silva, Libros, 141-169.

${ }^{28}$ La colección Araluce comprendía clásicos de literatura española, inglesa, griega hasta literatura oriental. Incluía libros como: la Odisea, Don Quijote, la Ilíada, Historias de Eurípides, El lazarillo de Tormes, El conde Lucanor, entre otros. Constatar en: BNC, “Circular”., 87

${ }^{29}$ Ibídem. Un análisis sobre los antecedentes y el proceso de construcción de la Selección de Daniel Samper Ortega de Literatura Colombiana puede encontrarse en: Miguel Ángel Pineda, "La edición de la Selección Samper Ortega de Literatura Colombiana. Biblioteca, editoriales e imprentas en la década de 1930”, Información, cultura y sociedad, N. 40 (junio, 2019). doi: $10.34096 /$ ics.i40.5181.

${ }^{30}$ Victoria E. Peters y Milena Trujillo A., "Rin Rin, revista infantil del Ministerio y Chanchito, revista ilustrada para niños. La dimensión de sus imágenes. Dos revistas de ideologías contrarias públicas durante la década de los treinta en Colombia”, Análisis vol. 50, nº. 92 (ene-jun 2018): 126. 
como lo muestra la correspondencia de la Biblioteca Nacional de Colombia ${ }^{31}$. El primer número de esta publicación fue editado en 1936 y dirigido por Sergio Trujillo $^{32}$.El nombre de esta publicación era un homenaje al renacuajo paseador, personaje de las fábulas del poeta Rafael Pombo, de ahí que en sus páginas se encontraran cuentos, cantos y canciones de él. ${ }^{33}$ Así, el objetivo principal de la publicación era:

construir un nuevo ciudadano, fundamental para consolidar la nueva nación moderna, Rin Rin acudió a diversas estrategias para configurarlo. La idea era fomentar la identidad nacional revalorizando la historia de los prohombres colombianos y dando a conocer las riquezas y la geografía de los distintos departamentos nacionales. La revista propuso formas ideales de comportamientos participativos; estimuló el fortalecimiento de la cultura física enseñando la higiene, las buenas prácticas alimenticias y la realización de actividades físicas, y promovió el espíritu optimista, alegre y colectivo de la infancia. ${ }^{34}$

Es así como la revista se convirtió en otro elemento de la política educativa del gobierno de López Pumarejo; en sus páginas promulgaba abiertamente las ideas liberales, lo que la convirtió en blanco de la crítica de los sectores más tradicionales del país, razón por la cual no siguió su edición ${ }^{35}$. La revista tuvo corta duración, solo se editaron 10 números entre 1936 y $1937^{36}$.

Los textos, que incluían libros, cartillas y revistas, fueron pensados sobre todo para los maestros, párrocos, médicos, alcaldes o concejales, quienes tenían la tarea de difundirlos e instruir a un público mucho más amplio con los conocimientos allí contenidos. Este conglomerado social se puede denominar,

${ }^{31}$ BNC, “Copiador de Correspondencia” (Bogotá, 1937): 55, 56, 57.

${ }^{32}$ Miguel Suárez "La revista Rin Rin y la difusión del proyecto educativo-cultural de Alfonso López Pumarejo”, en Nación, educación, universidad y manuales escolares en Colombia. Tendencias historiográficas contemporáneas, Jorge Conde Calderos, Luis Alarcón Meneses, Roberto Figueroa y Roberto González (comps.) (Barranquilla: Fondo de Publicaciones Universidad del Atlántico, 2002), 506.

${ }^{33} \mathrm{Ibídem}$. Hace poco tiempo, la Biblioteca Nacional de Colombia desarrolló una versión digital de las canciones y cuentos de la revista Rin Rin acompañados de las ilustraciones originales de la publicación, que se puede consultar en el siguiente enlace: http://bibliotecanacional. gov.co/es-co/colecciones/bibliografica/publicacion/rin-rin

${ }^{34}$ Peters y Trujillo, “Rin Rin”, 126.

${ }^{35}$ Suárez, "La revista Rin Rin", 508.

${ }^{36}$ Ibídem. 
en términos contemporáneos, como intermediarios sociales o mediadores culturales $^{37}$, quienes eran una especie de "anfibios" que vivían en dos culturas o sectores, apropiándose del saber impreso que conseguían difundir ${ }^{38}$.

A continuación, se analizará cómo se buscó generar, a través de las cartillas técnicas del Ministerio y de la revista Rin Rin, un proceso de trasformación sociocultural de las poblaciones del país, incluso en los lugares más apartados, con el objetivo de impulsar la modernización y el progreso. Este proceso se reflejó en la búsqueda de una trasformación del ciudadano pensado como un ser higiénico, fuerte y saludable.

\section{La higiene como factor de progreso en las cartillas técnicas y la revista Rin Rin}

Entre las colecciones que hacían parte de la Biblioteca Aldeana de Colombia se encontraban las cartillas técnicas que tenían como objetivo difundir nuevas prácticas en la vida cotidiana de los aldeanos. En ellas se incluían textos referentes a nociones generales sobre higiene, alimentación, educación física, cívica, religión, entre otros, que brindaban pautas sencillas para mejorar las condiciones físicas y biológicas del cuerpo. Entre ellas textos como Nociones de puericultura, por Calixto Torres Umaña: Nuestros alimentos, por varios autores; Edificaciones escolares y moblaje ¿Arquitectura aldeana y rural?, por Gonzalo Restrepo Álvarez; Educación fisica, por Rafael Tanco; Nociones básicas de escuela elemental, por G. Uribe ${ }^{39}$.

Para historiadores como Renán Silva, estos escritos llevaron a que profesionales de diversas disciplinas se interesaran por divulgar conocimientos propios de sus ramas a las personas del común. Este esfuerzo divulgativo se repartía entre los campesinos, como lo muestra el citado historiador:

Como lo indicaba en 1936 el Ministro de Educación, se trabajaba desde el año 1932 para que las misiones culturales que llevaban el cine a los pueblos las repartieran a los campesinos, habiendo enviado en ese año cien mil

\footnotetext{
${ }^{37}$ José Benito Garzón Montenegro, Mediadores interculturales y nación. El caso de las comunidades subalternas (Santiago de Cali: Universidad del Valle, 2013): 17.

${ }^{38}$ Herrera y Díaz, "Bibliotecas y lectores", 103-111.

${ }^{39}$ Para constatar, ver: BNC, "Circular", 87.
} 
ejemplares de tales folletos a todas las Bibliotecas Aldeanas y a muchísimas escuelas y colegios públicos ${ }^{40}$.

Con el proyecto de Cultura Aldeana y Rural, las escuelas y las bibliotecas aldeanas se concibieron, al menos para la elite intelectual y el liberalismo de la República Liberal, como espacios idóneos para impulsar, por medio de la producción editorial, una cultura de la higiene y de la alimentación ${ }^{41}$.

Así mismo, el gobierno liberal confiaba en que la educación era un mecanismo que le permitía trasformar el país y superar los altos niveles de analfabetismo, en lo que ese Ministerio jugaba un papel preponderante no solo para trasformar las costumbres sino para llevar al país hacia el progreso. Esto nos lleva a la fuerte creencia de que la educación era el vehículo a través del cual se resolverían los graves problemas sociales que aquejaban al [...] pais ${ }^{42}$.

Es por esto que la educación higiénica, impulsada desde finales del siglo XIX y principios del XX, buscó incidir en las costumbres de las poblaciones con el objetivo de mejorar las condiciones de salubridad pública. Este movimiento tuvo como principales impulsadores a los médicos que habían recibido una fuerte influencia de los preceptos de la medicina pasteuriana, cuyo centro de atención se concentró en las condiciones de vida de las poblaciones vulnerables porque eran consideradas como focos propagación de las enfermedades ${ }^{43}$.

Debido a esto, tanto la escuela como la familia se convirtieron en centro del discurso de control social que buscaba implementar la educación higiénica. Así como en el siglo XIX y bajo la idea del progreso, se buscó formar individuos disciplinados, diligentes, activos, respetuosos, responsables, sanos y bellos: La escuela se concibió entonces, como un espacio de encuentro del Estado y el pueblo en donde se podía controlar a la población y construir Nación. Para muchos, educar era higienizar, y la higiene era sinónimo de gobernar y poblar ${ }^{44}$.

${ }^{40}$ Renán Silva, "El libro popular en Colombia 1930-1948”,Revista de Estudios Sociales, N. 25 (2008): 25

${ }^{41}$ Luis Alarcón, Edwin Monsalvo y Miguel Suárez "La educación en marcha. El complejo establecimiento de las reformas educativas del gobierno de Alfonso López Pumarejo en el departamento del Atlántico (1934-1938)", Revista Latinoamericana de Estudios Educativos vol. 10, N. $^{\circ} 2$ (2014).

${ }^{42}$ Ibíd., 107.

${ }^{43}$ Luis Urteaga, "Higienismo y ambientalismo en la medicina decimonónica”, Acta Hispanica ad medicinae Scientiarumque Historiam Ilustradam vol. 5-6 (1985).

${ }^{44}$ Alejandra Valverde, "La educación en Colombia: un proyecto de nación moderna entre la higiene, la moral y la pedagogía”, Intertextos: cuadernos de comunicación social, N. 2 (2007): 103 
El objetivo era formar un tipo de sujeto ideal que respondiera a las necesidades del proyecto de Estado-nación que emprendieron los liberales de la primera mitad del siglo XX. Un ideal que implicaba la adaptación de prácticas higiénicas y saludables, nuevas formas de comportamiento, de alimentación y reordenamiento de los espacios habitacionales, un tipo de ciudadano moderno-civilizado ${ }^{45}$.

Razón por la cual, estas cartillas reflejaban la necesidad de homogeneizar unas normas básicas de conducta en las que se vieran irradiadas nuevas prácticas. Con ello, se buscaba cambiar los comportamientos "incivilizados", no solo de las poblaciones rurales, sino de toda la nación. Esta idea de fortalecer y cambiar las costumbres no es exclusiva del caso colombiano, tanto México ${ }^{46}$ como Ecuador ${ }^{47}$ buscaron implementar medidas científicas a través de la educación y las prácticas ya que las "disposiciones legislativas y las acciones gubernamentales eran ineficaces frente a la falta de una educación moral, intelectual e higiénica"48 (figura 01).

45 Zandra Pedraza considera que la civilidad contiene una visión total del ser humano, concebido en detalle, tanto en su constitución moral como en su apariencia física, en sus movimientos y su comportamiento social, e intenta a partir de allí una valoración del ser humano, de las sociedades y la historia. El discurso de la civilidad amalgama la vida individual y la social y cimenta la ética de su funcionamiento en el poder de los hábitos que incorpora en el individuo. Ver: Zandra Pedraza, "El régimen biopolítico en América Latina. Cuerpo y pensamiento social", Revista Iberoamericana vol. 4, N. ${ }^{\circ} 15$ (2004). doi: http://dx.doi. org/10.18441/ibam.4.2004.15.7-19. Fecha de consulta 22 de febrero del 2019.

${ }^{46}$ Claudia Agostini, "Discurso médico, cultura higiénica y la mujer en la ciudad de México al cambio de siglo (XIX-XX)”, Estudios mexicanos, N. ${ }^{\circ} 1$ (2002).

${ }^{47}$ Eduardo Kingman Garcés, La ciudad y los otros, Quito 1860-1940. Higienismo, ornato y policía. (Quito: Flacso/Fonsal, 2008).

${ }^{48}$ Agostini, "Discurso médico", 4. 
Figura N. ${ }^{\circ}$ 1. Higiene ${ }^{49}$

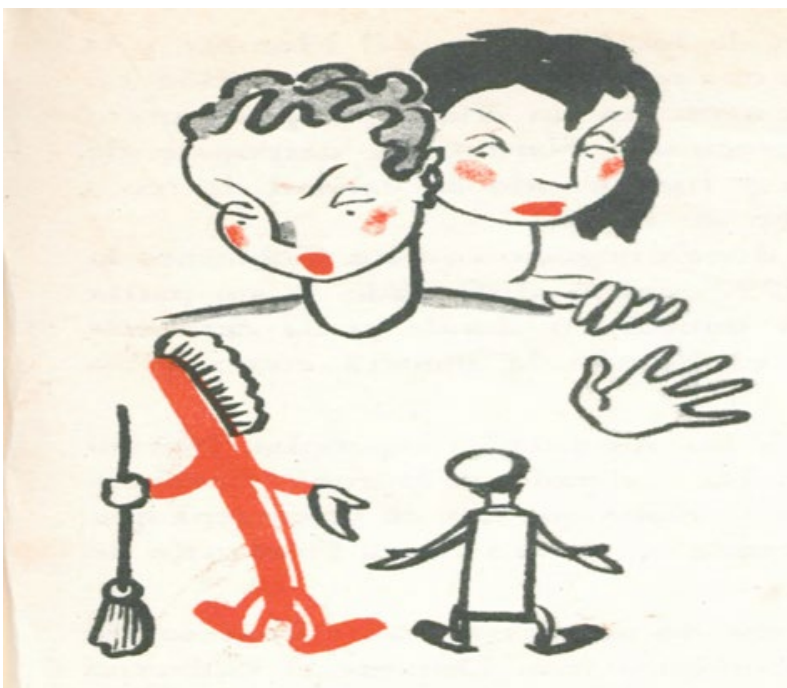

Al respecto y sobre algunas conductas o normas básicas de higiene para la conservación y el mantenimiento de un buen estado de salud, se recomendaba a los niños ser limpios y seguir las pautas más elementales del aseo personal, como lavarse las manos constantemente, cepillarse los dientes (ver Imagen N. 1) tres veces al día y bañarse con frecuencia:

Manos de todos mis queridos amiguitos, que anhelo activas, piadosas, nobles y muy limpias; manos en las que están el porvenir, la esperanza y la grandeza de la raza y de Colombia, debéis ser siempre pulcras. Y todos vosotros debéis manteneros como se mantiene este Rin-Rin: con el cuerpo bañado todos los días, los dientes sanos, las manos limpias y el corazón en $\mathrm{paz}^{50}$.

Puesto que La nueva generación colombiana que empieza a vivir tiene que ser muy limpia, muy austera y muy ejemplar ${ }^{51}$.

Así mismo, además de explicar el beneficio y la importancia que implicaba seguir las pautas que recomendaban sobre las nuevas prácticas que se debían incorporar, también se pusieron en evidencia en estos textos, por medio de

\footnotetext{
${ }^{49}$ MEN, Revista Rin-Rin, N. 2 (1936), 13.

${ }^{50}$ MEN, Rin-Rin, N. ${ }^{\circ} 7$ (1936), 4.

${ }^{51}$ MEN, Rin-Rin, N. 9 (1937), 2.
} 
ejemplos ilustrativos, las desventajas que se generaban por la no apropiación de los hábitos de higiene recomendados. Sobre este aspecto, una de las cartillas manifestaba que:

Toda persona, cualquiera que sea su edad, debe lavarse constantemente las manos, muchísimas veces, todas las que juzgue necesario. Esta sana y prudente costumbre la debemos adquirir desde niños. Para que sepáis lo que esto significa tengo que deciros también que se han dado casos de ceguera causados por haber restregado los ojos con unas manos contaminadas ${ }^{52}$.

Una persona mal presentada, ya porque no observe con cuidado en su cuerpo y en sus vestidos el hábito del aseo, ya porque ciertas enfermedades, adquiridas justamente por falta de higiene, nos la hagan repugnante, será siempre rechazada por sus semejantes y habrá labrado voluntariamente su propia desventura ${ }^{53}$.

Pero, no solo eran el cuerpo y la vestimenta lo que se debía intervenir si se querían obtener buenas prácticas, sino que los hogares, las escuelas y demás espacios de encuentro social en las aldeas también fueron considerados como epicentros de enfermedades por las malas condiciones de los mismos. Por lo cual, a través de las cartillas de higiene escolar, construcciones rurales y mobiliarios campesinos y civismo y buenas maneras, se buscaba promover una serie de actitudes en los niños con el objetivo de subsanar dicho problema. Se aconsejaba a las madres, por ejemplo:

Inculque en su hijo el amor por la ciudad en donde vive, haga que se preocupe por su limpieza y embellecimiento: esto despertará en él el sentido del civismo que es característico de los hombres cultos ${ }^{54}$.

[...] enseñe a su hijo a ser limpio moral y materialmente, no solo en sí mismo, sino en el ambiente que lo rodea: la pulcritud física y moral imprime carácter ${ }^{55}$.

\footnotetext{
${ }^{52}$ MEN, Rin-Rin, N. ${ }^{\circ} 7$ (1936), 3.

${ }^{53}$ MEN, Rin-Rin, N. ${ }^{\circ} 5$ (1936), 2.

${ }^{54}$ Eduardo Vasco Gutiérrez, Educación del carácter. Biblioteca Aldeana de Colombia (Bogotá: Ministerio de Educación Nacional,1935), 51.

${ }^{55}$ Vasco, Educación, 46.
} 
Así mismo, con estas cartillas, se procuraba introducir en las aldeas nuevas formas arquitectónicas y estéticas, en función de los patrones de construcción de las ciudades modernas, con el objetivo de crear espacios sanos. Sobre las construcciones escolares, se planteaba que:

El aula o clase, sitio donde el niño permanece la mayor parte del tiempo, tiene que ajustarse a las más estrictas reglas de la higiene.

Su forma debe ser rectangular en proporción de dos por tres o tres por cinco. Su profundidad debe atender ante todo la iluminación, de manera que en cualquier punto de la clase se pueda leer con mayor facilidad. Prelat limita la anchura del aula a 6 metros 50 centímetros; en general nunca debe exceder del duplo de la altura. La longitud no será mayor de 9 a 10 metros. El reglamento de Múnich ordena: 8 de longitud, 6 de anchura y 4 de altura, a pesar de que un niño colocado a 8 metros del tablero ya está en malas condiciones para leer ${ }^{56}$.

Con las cartillas técnicas sobre alimentación, se buscaba promover un régimen alimentario acorde a las necesidades y comodidades de las personas. Se trataba de formar un nuevo estilo de vida en las aldeas a partir de nuevas prácticas nutricionales, puesto que una población bien alimentada tenía menos tendencias a enfermarse y, por lo tanto, en términos económicos, era más activa y productiva. La cartilla recomendaba que:

La alimentación debe ser variada y bien equilibrada para producir resultados compensadores. Cambia de acuerdo con la edad, el clima, el estado de salud y las necesidades del cuerpo de cada persona ${ }^{57}$.

No hay salud perfecta sin alimentación escogida y variada. En cualquier régimen es indispensable el uso de frutas crudas, verduras y legumbres frescas. Comamos naranjas, bananos, papaya, aguacate, mango, espinaca, lechugas, coles, tomates, coliflor, zanahorias ${ }^{58}$.

${ }^{56}$ Luis E. Aldana, Algo sobre higiene escolar. Biblioteca Aldeana de Colombia (Bogotá: Ministerio de Educación Nacional, 1935), 11. Este texto hizo parte de la colección de cartillas técnicas de las bibliotecas aldeanas, pero cabe anotar que fue el resultado de su tesis para aspirar al título de Doctor en Medicina y Cirugía en la Universidad Nacional en 1921.

${ }^{57}$ Varios Autores, Nuestros alimentos. Biblioteca Aldeana de Colombia (Bogotá: Ministerio de Educación Nacional, 1935), 15.

${ }^{58}$ Ibíd., 100. 
Esta forma de concientizar a la población sobre los beneficios que traía una buena alimentación para la salud era repetida constantemente en las cartillas; idea que se encontraba basada en una construcción discursiva alrededor de las ventajas y desventajas de llevar o no un buen régimen alimenticio. Un ejemplo muy diciente al respecto planteaba que:

Así como una deficiente alimentación enflaquece el organismo y empobrece el cuerpo, una superalimentación o una alimentación anormal causa enfermedades que llevan muchas veces a la miseria y a la muerte. Un buen régimen alimenticio es la más segura garantía de vida y de perfecta salud $^{59}$.

Pero, el problema alimenticio no solo era algo que afectaba al individuo y su desarrollo, sino que era un factor que impedía la capacidad de los seres humanos de trabajar en equipo, afectando incluso la salud mental. Así se muestra en el siguiente apartado:

El espíritu de sociabilidad es espontáneo en el individuo sano. Sólo los débiles pierden la calma y el valor. Solo los raquíticos se contrarían, se sienten amedrantados, se abaten. Muchas enfermedades nerviosas y mentales provienen de la inestabilidad emotiva, del mal humor, de los caprichos, de la ociosidad ${ }^{60}$.

La mala alimentación en los espacios rurales no era atribuida solamente a la pobreza, sino también a la ignorancia y al descuido que existía en materia de alimentación, lo que impedía que tuvieran un estado de salud deseable. Por ello, la cartilla trataba de concientizar a sus destinatarios, sobre qué tipo de alimentos servían para obtener una buena nutrición: [...] Aprovechemos el dinero destinado a los alimentos, adquiriendo los que son verdaderamente útiles al organismo. Gastemos menos en carne y dulces, y compremos más leche, legumbres, verduras, frutas y huevos ${ }^{61}$.

Además de los consejos alimenticios, las cartillas incorporaban conocimientos fisiológicos y recomendaciones acerca de algunas conductas que debían seguirse para el buen funcionamiento del sistema digestivo y el desarrollo del cuerpo. No se trataba solo de impulsar un régimen nutritivo para

\footnotetext{
${ }^{59}$ Ibíd., 16.

${ }^{60}$ Ibíd., 7.

${ }^{61}$ Ibíd., 101.
} 
la población a través de estos textos, sino, también, nuevos tipos de conductas que le permitieran a la sociedad vivir mejor. Por ejemplo, se recomendaba que:

Antes de las comidas, y especialmente por la tarde, reposemos un poco. Comer fatigados es cosa perjudicial para el organismo. Este es uno de los mejores consejos sobre la alimentación ${ }^{62}$.

Comamos despacio y masticando muy bien. El aprovechamiento de los alimentos depende de la buena digestión. Para que los alimentos sean digeridos se necesita que estén bien masticados y convenientemente empapados en saliva [...] Es preciso hacer las refecciones de cuatro en cuatro horas, para dar tiempo a que el estómago se desocupe. Alimentarse cuando está todavía lleno, fatiga aquel órgano y perturba la digestión ${ }^{63}$.

Pero la alimentación no fue lo único a lo que se le prestó importancia; otro elemento que se señalaba era la responsabilidad asignada a las mujeres en su rol maternal, ya que eran las encargadas de preservar y defender la raza frente a los achaques de salud ${ }^{64}$. Este rol estaba mucho más claro en las cartillas de puericultura que intentaron convertirse en textos guías para el ejercicio de la maternidad. El objeto de estas cartillas era enseñar a las mujeres conocimientos sobre el cuidado de los niños:

Es sobre todo a la mujer, en cuyo organismo reside el molde sacro de la raza y de cuya pericia depende, en grado sumo, el porvenir físico del niño, a quien están destinadas las páginas de esta cartilla, en las que encontraran los más elementales y más indispensables conocimientos de puericultura, sin los cuales no tiene derecho a aspirar a la maternidad ${ }^{65}$.

La cartilla Nociones de puericultura se ocupó de temas relacionados con el cuidado y las precauciones que debía tener la mujer embarazada; asimismo, se le dedicó especial atención al cuidado y a la importancia de la higiene del infante, la lactancia materna y las reglas dietéticas que debían seguir al

${ }^{62}$ Ibíd., 103.

${ }^{63}$ Ibíd., 104.

${ }^{64}$ Ángela Lucía Agudelo “Regenerar e higienizar. El papel desempeñado por la mujer y la niñez en Barranquilla 1900 - 1945", Memorias vol. 5, N. ${ }^{\circ} 9$ (2008), http://rcientificas.uninorte.edu. co/index.php/memorias/article/view/439/226. Fecha de consulta: 30 de enero de 2019.

${ }^{65}$ Calixto Torres Umaña y Eduardo Vasco, Nociones de puericultura. Biblioteca Aldeana de Colombia (Bogotá: Ministerio de Educación Nacional, 1935), 2. 
momento del destete. Se buscó por medio de estas cartillas brindar nociones elementales para corregir y perfeccionar el papel de las madres con respecto al cuidado de los niños, consideradas, para la época, como las responsables de la preservación de la raza.

Esta idea de perfeccionar el papel de las madres estaba anclado a la idea de consolidar un nuevo modelo de maternidad que se ajustara a los avances hechos por los médicos; esta idea no solo se desarrolló en las zonas rurales, sino también en las ciudades. Entre algunas recomendaciones sobre las reglas dietéticas que debían seguir al destete, se planteaba que:

Contra el error de destetar al niño prematuramente, reaccionan algunas madres con el opuesto error de querer amamantar a su hijo por más de uno o dos años sin darle más alimento que leche materna.

Es esta una práctica funesta, no solo porque la leche llega a ser cualitativamente insuficiente, por grandes que sean las cantidades que se suministren al mamón, sino por otra razón por lo menos tan importante como ésta: porque las reservas de hierro que el niño trae consigo a la vida empiezan a escasearse entre los ocho y los doce meses, si el niño ha nacido a término, mucho antes si ha venido prematuramente al mundo; y la leche no contiene sino una mínima parte del hierro que el pequeño organismo necesita para reparar los glóbulos rojos de su sangre que diariamente son destruidos por ciertas glándulas, en el proceso fatal de destrucción que encarna el equilibrio mismo de la vida. La hemoglobina - elemento esencialmente ferruginoso que resulta de esta destrucciónes transformada en diversos pigmentos de imprescindible eliminación.

Se hace, pues, indispensable introducir, hacia los ocho meses de edad de la criatura, un alimento que contenga hierro en cantidades necesarias, Estos alimentos son sobre todo de origen vegetal; pero la mayoría son sustancias harinosas, cuya introducción en la alimentación del niño no se puede hacer intempestivamente o sin temperancia, como suelen hacerlo las personas que proceden con la imprudencia que da el desconocimiento de los peligros ${ }^{66}$.

Esta larga cita nos muestra cómo los médicos de la época se convirtieron no solo en una autoridad moral, sino científica. Su aparición como autores de las cartillas les otorgó centralidad en el proceso de consolidación del proyecto

${ }^{66}$ Torres y Vasco, Nociones, 13. 
progresista liberal colombiano ${ }^{67}$. Es así como el discurso médico ganó un espacio nuevo en la sociedad y se legitimó al proyectarse no sólo como discurso moral sino como discurso útil para el progreso y bienestar de los ciudadanos ${ }^{68}$.

Los textos aquí analizados, más allá de explicar las nociones fundamentales acerca de la higiene, la alimentación y la puericultura, buscaban, al mismo tiempo, impulsar una cultura de prevención sobre la población con el objetivo generar un proceso de trasformación sociocultural que permitiera a la sociedad adelantar un proceso de modernización.

\section{Reflexiones finales}

Las cartillas fueron pensadas como un mecanismo que permitía generar un tipo de colombiano ideal. Que buscaba consolidar el progreso mediante el seguimiento de unas nociones básicas de higiene para la vida en sociedad y unos modelos de conducta social con el propósito de construir nuevas prácticas civilizadoras y urbanísticas encaminadas a una transformación cultural con miras al progreso y la civilización.

Con estos textos se buscó difundir nuevas formas de comportamiento en los aldeanos, cambiar o transformar sus prácticas higiénicas, alimenticias, estéticas y hasta perfeccionar el modelo de maternidad con el objetivo de construir cuerpos sanos, civilizados y disciplinados.

Textos que hicieron parte de la Biblioteca de Cultura Aldeana, producto del gobierno de López Pumarejo que buscó a través de la educación consolidar un proyecto modernizador por medio de la lectura. Fueron pensados para un público campesino poco alfabetizado o a grupos urbanos que tampoco tenían gran experiencia en su relación con el mundo del libro ${ }^{69}$, se trataba de poblaciones vulnerables, susceptibles de intervención para consolidar la modernización y el progreso en el país.

Como han demostrado algunas investigaciones, este proceso de implementación de la política educativa del primer gobierno de López Pumarejo se encontró con grandes obstáculos en su aplicación en las regiones de Colombia ${ }^{70}$. Sin embargo, este artículo no centró su mirada en el citado punto, por el contrario, se mostró la preocupación generada por el Estado de

${ }^{67}$ Jairo Solano y Emilio Quevedo, La medicina en la historia y la sociedad en Barranquilla 1865-

1965 (Barranquilla: Ediciones Universidad Simón Bolívar, 2011).

${ }^{68}$ Catalina Reyes, La vida cotidiana en Medellín 1890-1930 (Bogotá: Colcultura, 1996), 115.

${ }^{69}$ Renán Silva, El libro popular, 26.

${ }^{70}$ Alarcón, Monsalvo y Suárez “La educación”, 97-123. 
tratar de trasformar, a través de la educación, las prácticas y costumbres de las poblaciones vulnerables y consolidar así los procesos de modernización del país.

\section{Referencias bibliográficas}

\section{Fuentes primarias}

Biblioteca Nacional de Colombia, "Copiador de Correspondencia” (Bogotá, 1937).

Ley 32 de febrero 20 de 1936. "Sobre igualdad de condiciones para el ingreso a los establecimientos de educación” Diario Oficial No. 23127 (5 de marzo de 1936).

Ministerio de Educación Nacional (MEN) Memoria del ministro de Educación Nacional. (Bogotá: MEN, 1935).

Revista Senderos, 1934-1935.

Revista Rin Rin 1936-1937.

Vasco, Eduardo. Educación del carácter. Biblioteca Aldeana de Colombia. Bogotá:Ministerio de Educación Nacional, 1935.

Varios autores Nuestros alimentos. Biblioteca Aldeana de Colombia. Bogotá: Ministerio de Educación Nacional, 1935.

Torres Umaña Calixto y Vasco Gutiérrez, Eduardo. Nociones de puericultura. Biblioteca Aldeana de Colombia. Bogotá: Ministerio de Educación Nacional, 1935.

\section{Fuentes secundarias}

Alarcón, Luis Edwin Monsalvo y Miguel Suárez. "La educación en marcha. El complejo establecimiento de las reformas educativas del gobierno de Alfonso López Pumarejo en el departamento del Atlántico (1934-1938)”. Revista Latinoamericana de Estudios Educativos vol. 10, N. . 2 (2014): 97-123.

Agostini, Claudia. "Discurso médico, cultura higiénica y la mujer en la ciudad de México al cambio de siglo (XIX-XX)”. Estudios mexicanos, N. ${ }^{\circ} 1$ (2002): $1-22$.

Agudelo, Ángela Lucía. "Regenerar e higienizar. El papel desempeñado por la mujer y la niñez en Barranquilla 1900 - 1945”. Memorias vol. 5, N. 9 (2008). http:// rcientificas.uninorte.edu.co/index.php/memorias/article/view/439/226

Burke, Peter. Historia social del conocimiento. De Gutenberg a Diderot. Barcelona: Paidós, 2002.

Chapman Quevedo, William Alfredo, Sandra Milena Ariño Solano y Korge Eliécer Cruz Ortiz. Pitalito 200 años de historia. Ibagué: Caza de Libros, 2018.

Darnton, Robert. El diablo en el agua bendita o el arte de la calumnia de Luis XIV a Napoleón. México D. F.: Fondo de Cultura Económica, 2014.

Díaz, Carlos J. El pueblo: de sujeto dado a sujeto político por construir. El caso de la "Campaña de Cultura Aldeana” en Colombia (1934-1936). Bogotá: Universidad Pedagógica Nacional, 2005. 
Díaz, Carlos J. “La Campaña de la Cultura Aldeana (1934-1936) en la historiografía de la educación colombiana”. Revista colombiana de Educación, N. . 38-39 (1999). doi: https://doi.org/10.17227/01203916.5435

Elías, Norbert. El proceso de la civilización: investigaciones sociogenéticas y psicogenéticas. México D. F.: Fondo de Cultura Económica, 1987.

Garzón Montenegro, José Benito. Mediadores interculturales y nación. El caso de las comunidades subalternas. Santiago de Cali: Universidad del Valle, 2013.

Giraldo, César. Primera administración López Pumarejo: "La Revolución en Marcha”, Desarrollo económico y social en Colombia. Siglo XX. Bogotá: Universidad Nacional de Colombia, 2001.

Herrera, Martha Cecilia y Carlos Jilmar Díaz. "Bibliotecas y lectores en el siglo XX colombiano: la Biblioteca Aldeana de Colombia”, Revista Educación y Pedagogía,

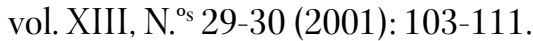

Kingman Garcés, Eduardo. La ciudad y los otros, Quito 1860-1940. Higienismo, ornato y policía. Quito: Flacso/Fonsal, 2008.

Lanzillotta, María de los Ángeles y Micaela Oviedo. “'Difundir cultura e ilustración'. Las bibliotecas populares en la trama de la sociabilidad de las poblaciones pampeanas, 1905-1955". Historia y Espacio vol. 14, n. ${ }^{\circ} 51$ (2018): 75-107. doi: https:// doi.org/10.25100/hye.v14i51.6985

Loaiza Cano, Gilberto. Sociabilidad, religión y política en la definición de la nación. Colombia, 1820-1886. Bogotá: Universidad Externado de Colombia, 2011.

Mora Toscano, Oliver. "Los dos gobiernos de Alfonso López Pumarejo: Estado, reformas económicas y sociales en Colombia (1934-1938) -(1942-1945)”. Revista Apuntes del Cenes vol. 36, N. . 64 (2017): 151-171.

Pedraza, Zandra. "El régimen biopolítico en América Latina. Cuerpo y pensamiento social" Revista Iberoamericana vol. 4, N. 15 (2004). doi: https://dx.doi. org/10.18441/ibam.4.2004.15.7-19

Peters, Victoria E. y Milena Trujillo. "Rin Rin, revista infantil del Ministerio y Chanchito, revista ilustrada para niños. La dimensión de sus imágenes. Dos revistas de ideologías contrarias públicas durante la década de los treinta en Colombia”. Análisis vol. 50, N. 92 (2018): 119-143.

Pineda, Miguel Ángel “La edición de la Selección Samper Ortega de Literatura Colombiana. Biblioteca, editoriales e imprentas en la década de 1930". Información, cultura y sociedad, N. ${ }^{\circ} 40$ (jun, 2019): 69-92

Prado Arellano, Luis Ervin. “El letrado parroquial”. En El siglo diecinueve colombiano, editado por Isidro Vanegas. Bogotá D. C.: Ediciones Plural, 2017, 99-124.

Reyes, Catalina. La vida cotidiana en Medellin 1890-1930. Bogotá: Colcultura, 1996.

Sáenz, Javier. "Reformas normalistas de la primera mitad de siglo (1903-1946)". Revista Educación y Pedagogía, ‥ os 14 y 15 (1995): 154-169.

Silva, Renán. “Libros y lecturas durante la República Liberal: Colombia, 1930-1946”. Revista Sociedad y Economía, N. 3 (2002): 141-169.

Silva, Renán. "El libro popular en Colombia 1930-1948”, Revista de Estudios Sociales. N. 25 (2008) 20-37. 
Solano, Jairo y Emilio Quevedo. La medicina en la historia y la sociedad en Barranquilla 1865-1965. Barranquilla: Ediciones Universidad Simón Bolívar, 2011.

Suárez, Miguel. "La revista Rin Rin y la difusión del proyecto educativo-cultural de Alfonso López Pumarejo”. En Nación, educación, universidad y manuales escolares en Colombia. Tendencias historiográficas contemporáneas. Compilado por Jorge Conde Calderos, Luis Alarcón Meneses, Roberto Figueroa y Roberto González. Barranquilla: Fondo de Publicaciones Universidad del Atlántico, 2002.

Urteaga, Luis. "Higienismo y ambientalismo en la medicina decimonónica”. Acta Hispanica ad medicinae Scientiarumque Historiam Ilustradam, vol. 5-6 (1985): 417-425.

Valverde, Alejandra. "La educación en Colombia: un proyecto de nación moderna entre la higiene, la moral y la pedagogía”. Intertextos: cuadernos de comunicación social, N. ${ }^{\circ} 2$ (2007): 1-15. 
